\title{
Variations in melt-layer frequency in the GISP2 ice core: implications for Holocene summer temperatures in central Greenland
}

\author{
Richard B. Alley and Sridhar Anandakrishnan \\ Earth System Science Center and Department of Geosciences, The Pennsylvania State University, University Park, \\ PA 16802, U.S.A.
}

\begin{abstract}
The rare melt features in the GISP2, central Greenland deep ice core have decreased in frequency over the most recent 7000 years. Calibration of this change in melt frequency against modern spatial variation of melt frequency and temperature in central Greenland, and against modern temporal variability of temperatures in central Greenland, indicates that mean mid-summer temperatures have cooled over the most recent 7000 years, probably by slightly more than $1^{\circ} \mathrm{C}$ if variability of summer temperatures has not changed. Comparison to GRIP isotopic records from central Greenland and to the melt record from the Agassiz Ice Cap, Arctic Canada, suggests some seasonal and regional coherence for this cooling signal, as well as for a cold event about $8000-8500 \mathrm{BP}$.
\end{abstract}

\section{INTRODUCTION}

The occurrence of a melt layer in an ice core indicates summertime warmth in excess of some threshold value (e.g. Langway, 1967). Melt features are easy to recognize and count, and several authors have produced informative time series of ice-core melt (e.g. Koerner, 1977; Herron and others, 1981; Koerner and Fisher, 1990; Fisher, 1992; Kameda and others, 1995). These studies show, for example, extensive melting on Canadian Arctic ice caps during the early to middle Holocene, and periods of reduced and enhanced melting during certain decades or centuries over the most recent millennia that may correlate with such "classical" climatic events as the Little Ice Age, the Medieval Warm Period and perhaps even anthropogenic warming.

Calibration of melt as a thermometer poses some difficulties. One technique is to measure mean annual temperature (or mean summer temperature or some other temperature indicator) and frequency of melting (or total thickness of melt, or some other melt indicator) at different sites today, use regression analysis to learn the dependence of melt on temperature, and assume that this modern spatial dependence has applied at a single site over time (e.g. Koerner and Fisher, 1990). This is essentially the same assumption made in most studies using stable-isotopic paleothermometry, where it has proven relatively accurate in most cases (e.g. Cuffey and others, 1992, 1994; but see Peel and others, 1988).

Extensive physical studies of the new Greenland Ice Sheet Project II (GISP2) deep ice core from central Greenland (e.g. Alley and others, 1993; Gow and others, 1993) included visible examination of the core for melt features. Here, we report the melt-feature data, and we estimate summertime temperature change during the Holocene.

\section{METHODS}

The GISP2 ice core was drilled during the summers of $1989-93$ at $72.6^{\circ} \mathrm{N}, 38.5^{\circ} \mathrm{W}, 3200 \mathrm{~m}$ elevation, $28 \mathrm{~km}$ west of the summit of the Greenland ice sheet, by the Polar Ice Coring Office. Mean annual $(20 \mathrm{~m})$ temperature is about $-31.4^{\circ} \mathrm{C}$, and accumulation is about $240 \mathrm{~mm}$ ice $^{-1}$ (Alley and Koci, 1988; Alley and others, 1993). Dating is from Alley and others (1993).

The core was sliced longitudinally on a band-saw, microtomed and examined on a light table. All of the core was examined in the field by a physical-properties researcher from the U.S. Army Cold Regions Research and Engineering Laboratory (CRREL) or from Penn State. Much of the core was re-examined at the U.S. National Ice Core Laboratory in Denver, CO, U.S.A., during studies of reproducibility of field observations. In particular, one of us (R.B.A.) has examined all Holocene and late-glacial core at least once, and many core sections more than once. For consistency, the results reported here come from the observations by R.B.A.; other workers (A.J. Gow, D. A. Meese and C. A. Shuman) identified exactly the same melt features in the sections they studied.

Melt features in the core are recognized as nearlybubble-free zones. These zones are usually somewhat irregular or lenticular in appearance, may include elongate bubbles in contrast to the more-nearly-spherical bubbles of most ice, and often contain relatively large grains and bubbles compared to their neighbors. Melt 
features are observed to occur in firn and ice deposited during summertime, based on comparison to summers identified by their depth-hoar signature or other chemical, isotopic or particulate indicators (Taylor and others, 1992; Alley and others, 1993). In warmer regions, summer meltwater may percolate into firn from the winter or from a previous year (e.g. Benson, 1962), but that does not appear to occur in the low-melt but highaccumulation environment at GISP2. Melt features were not observed with visible ash or dust that might have promoted surface melting by altering the albedo Gow and Williamson, 1971).

One difficulty is caused by the occurrence of crusts in the core. These are bubble-free zones only a single grain in thickness (usually $1 \mathrm{~mm}$ in thickness or less) that have been observed in ice from various times of the year. The origin of individual crusts is often uncertain; they are probably polygenetic - glazing by wind action, slight melting, drizzle, riming, vapor transfer or other processes may be responsible (e.g. Benson, 1962; Langway, 1967; Gow, 1968; Fujii and Kusunoki, 1982). To avoid crusts, we confine attention to features greater than $2 \mathrm{~mm}$ in thickness at time of deposition. (Flow thinning would have approximately halved that thickness in ice from the earliest Holocene (Schøtt and others, 1992). Crusts thicker than $2 \mathrm{~mm}$ can occur, although in our experience they are rare or absent at GISP2.) Features identified as melt based on thickness typically show other characteristics indicative of true melt, such as large grains, abnormally large or elongated bubbles, and lenticular form.

Ice from the early part of the Holocene contained few bubbles when first extracted from the ice sheet, owing to enclathratization of the air in the bubbles. Relaxation of the core allowed reappearance of bubbles. Our count of melt features for this ice is based on observations after 2 years of relaxation. Some melt layers did appear or become more evident during relaxation. We cannot guarantee that all layers had become identifiable after 2 years of storage, however; the details of formation and dissociation of clathrates in natural ice are not known that well. The data from $0-8000 \mathrm{BP}$ are from ice that was highly bubbly in situ, and so are reliable. Bubble loss to clathrate formation is a gradual process over hundreds of years or more; we believe that our data are reliable to at least $8500-9000 \mathrm{BP}$ and probably longer, but we cannot be sure of this.

Because melt is scarce in the GISP2 core compared to cores from warmer sites such as Devon Island or Dye 3 (Koerner, 1977; Herron and others, 1981), we have chosen to record the occurrence of melt in a year rather than the total melt thickness or melt fraction. This avoids difficult decisions about how to measure thickness of lenticular or irregular features. Because we cannot tell whether two melt features a few millimeters apart within ice from a single summer formed in two events or in one event with percolation connecting the two, we simply record presence or absence of melt in each summer layer.

\section{RESULTS}

The observed melt frequency for the most recent $10 \mathrm{ka}$ (the upper $1565 \mathrm{~m}$ of the core) is shown in Figure 1.
Melting is clearly scarce, averaging 1 event per 153 a over this time and supporting the classification of Benson (1962) that this site falls within the dry-firn zone. Examination of older ice, including ice from the Bolling/Allerod warm period, revealed no melt features. Melting was clearly more frequent $7-8 \mathrm{kaBP}$ than recently; we discuss the possible significance of older changes in melt frequency below.

We first test whether the decrease in melt frequency over the most recent $7 \mathrm{ka}$ is statistically significant, by looking at $3 \mathrm{ka}$ sections of the record. The frequency of melt features is highest from 5500 to $8500 \mathrm{BP}$ (mean spacing of $82 \mathrm{a}$ ) and lower than this more recently (mean spacing of $250 \mathrm{a}$ from 1000 to $4000 \mathrm{BP}$ ).

We compare this change to the results of a Monte Carlo simulation. Rare events such as the melting observed here should be described by a Poisson distribution, so we randomly generated 10000 Poisson-distributed time series, each $3 \mathrm{ka}$ long and selected from a population with a mean spacing between events of $153 \mathrm{a}$. We then fit a normal distribution to the histogram of the mean event spacings of these randomly generated time series and estimated the standard deviation. The observed recent frequency of 1 event per 250 a over $3 \mathrm{ka}$ is two standard deviations below the mean, and the observed peak level of 1 event per $82 \mathrm{a}$ over $3 \mathrm{ka}$ is 1.5 standard deviations above the mean. The probability of obtaining two such extreme values in a time series only $10 \mathrm{ka}$ long is quite small, so we conclude that the melt frequency has decreased toward the present.

A similar conclusion applies to the increase in melt frequency from $9000-12000$ to $5500-8500 \mathrm{BP}$, if clathraterelated processes have not corrupted the data. In some calculations below we use shorter averaging times than $3 \mathrm{ka}$, because the climate changes observed in other indicators such as stable isotopic ratios are shorter than $3 \mathrm{ka}$; however, we avoid very-high-resolution analyses because they would lack statistical significance.

\section{CALIBRATION}

We attempt to calibrate the variation in melt frequency in two ways. Both include untested assumptions, and so an unknown degree of uncertainty is attached to the results. Consistency of the results increases our confidence in the calibration. The basic result, a cooling of roughly $1^{\circ} \mathrm{C}$ or slightly more over the latter part of the Holocene, appears relatively insensitive to most of these assumptions and thus quite robust.

Alley and Koci (1988) studied two shallow cores from site A, Greenland $\left(70.8^{\circ} \mathrm{N}, 36.0^{\circ} \mathrm{W}, 3145 \mathrm{~m}\right.$ elevation $)$, slightly south and east of the GISP2 site. Mean annual $(20 \mathrm{~m})$ temperature at site $\mathrm{A}$ is approximately $-29.4^{\circ} \mathrm{C}$, about $2^{\circ} \mathrm{C}$ warmer than the mean annual $(20 \mathrm{~m})$ temperature at the GISP2 site. One core was studied in detail, and the other only briefly. The one studied in detail contained nine years with melt in the most recent $300 \mathrm{a}$, which is more frequent than for the peak Holocene value at GISP2. If the spatial dependence of melt on temperature between GISP2 and site A applied over time at GISP2, and if the difference in mid-summer temperatures between GISP2 and site $\mathrm{A}$ is the same as the 
difference in mean annual temperatures $\left(2^{\circ} \mathrm{C}\right)$, then the mid-summer temperature change at GISP2 from $7000 \mathrm{BP}$ to the present must be less than $2^{\circ} \mathrm{C}$.

It is a reasonable assumption that melting is a probabilistic process, and thus that frequency of melting varies with temperature according to a probability distribution. Lacking better data, we assume a normal distribution for interpolating between site A and GISP2 conditions. Linear interpolation, the other "obvious" choice, would imply a triangular probability-density function, which is unlikely to occur in Nature. We note below, however, that linear interpolation gives a result not too different from that for a normal distribution.

The melt frequency over the most recent few thousand years at GISP2 is $1 / 250 \mathrm{a}$, about 7.5 -fold lower than the $9 / 300 \mathrm{a}$ at site A. (A longer averaging time is appropriate at GISP2 because of the rarity of events. A longer averaging time is not possible at site A because the core was not deep enough. However, the most recent $300 \mathrm{a}$ at GISP2 contain one melt event, giving a nine-fold change from GISP2 to site A over this 300 a period, not greatly different from the 7.5-fold change we adopt.) Assuming that the summertime temperatures have the same standard deviation for GISP2 and site A over the study period, that standard deviation must be $3.5^{\circ} \mathrm{C}$ so that a $2^{\circ} \mathrm{C}$ increase in temperature causes a 7.5 -fold increase in melt frequency, based on examination of standard statistical tables for the integral of the normal distribution. The peak melt frequency at GISP2 is $4 / 250$ a from the 1000 a average in Figure 1, yielding a cooling at GISP2 over the last $7 \mathrm{ka}$ of about $1.3^{\circ} \mathrm{C}$, again based on examination of standard statistical tables for the integral of the normal distribution. The uncertainty arising from our choice of averaging lengths and the assumed probability distribution is probably in the range of a few tenths of a degree. A simple linear interpolation would yield a cooling of $0.9^{\circ} \mathrm{C}$ rather than the $1.3^{\circ} \mathrm{C}$ from the normal-distribution probabilistic interpolation.

A second way to estimate the standard deviation is from modern summertime temperatures. Suppose that a melt feature requires one hot day to form, that the "summer" (the time during which sufficiently hot days are likely to occur) is $40 \mathrm{~d}$ long (based on inspection of Automatic Weather Station data from central Greenland; unpublished information from C. Stearns, 1993), and that the mean temperatures for these summer days are normally distributed. Automatic Weather Station data from the GISP2 site (unpublished information from C. Stearns) show that mean daily temperatures from late June to early August have a standard deviation of about $3^{\circ}$ to $4^{\circ} \mathrm{C}$, essentially indistinguishable from the estimate based on the site A calibration. Again assuming a stationary standard deviation and normally distributed temperatures, the change in melt frequency from $7000 \mathrm{BP}$ to the present indicates a cooling of $1.1^{\circ}$ to $1.5^{\circ} \mathrm{C}$.

If we continue to assume that summertime temperatures are normally distributed, but allow the standard deviation to vary from an assumed modern value of $3.5^{\circ} \mathrm{C}$, we obtain $\Delta T=1.30-3.35 \Delta \sigma$, where $\Delta T$ is the temperature change in ${ }^{\circ} \mathrm{C}$ from about $7000 \mathrm{BP}$ to the late Holocene, positive for cooling, and $\Delta \sigma$ is the change in

\section{GISP2 Holocene Melt Years}
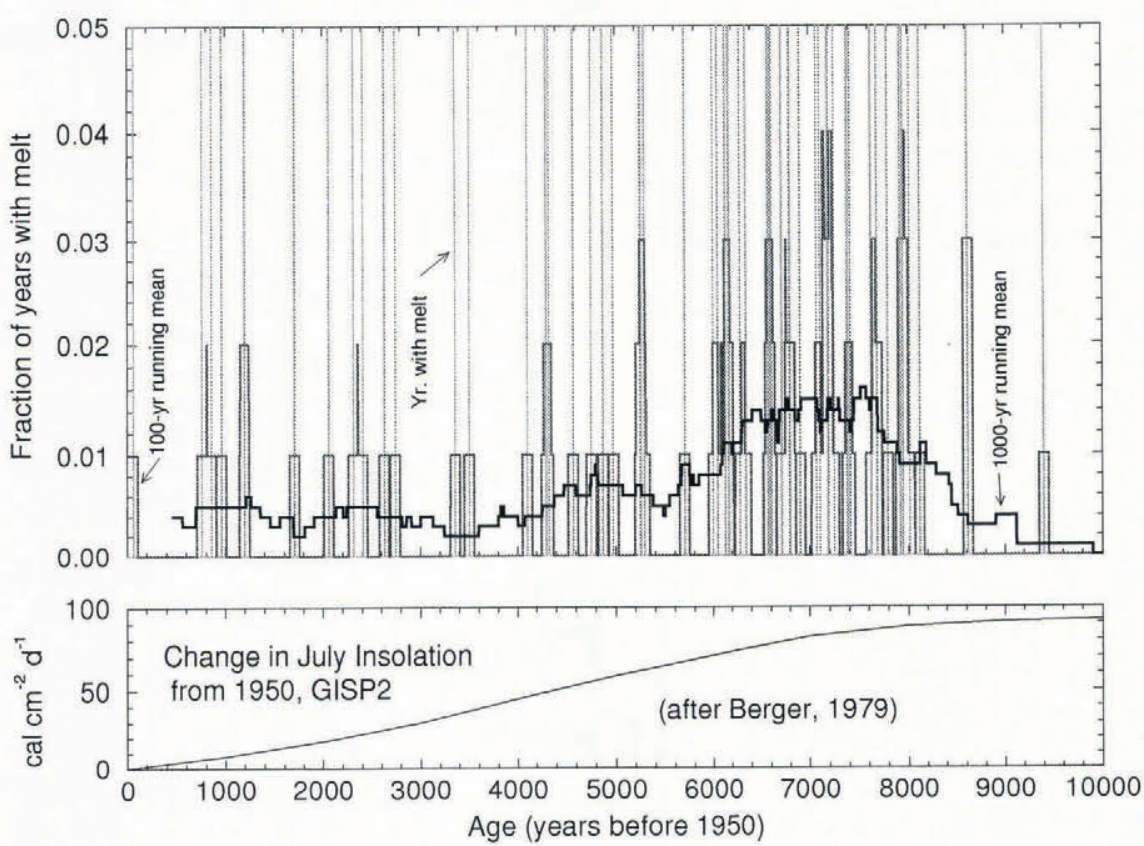

Fig. 1. Melt against age (upper panel) and July insolation against age (lower panel) for the GISP2 site. Years containing melt features are shown by thin dotted lines. The heavier textured line is the 100 a running mean of melt frequency (number of melt features per 100 a), and the heavy black line is the 1000 a running mean. The lower panel shows deviation of July insolation from modern values in cal cm ${ }^{-2} d^{-1}$, from Berger $(1978,1979)$; positive values indicate more insolation than today. 
standard deviation in ${ }^{\circ} \mathrm{C}$, positive for a decrease toward the present (Fig. 2).

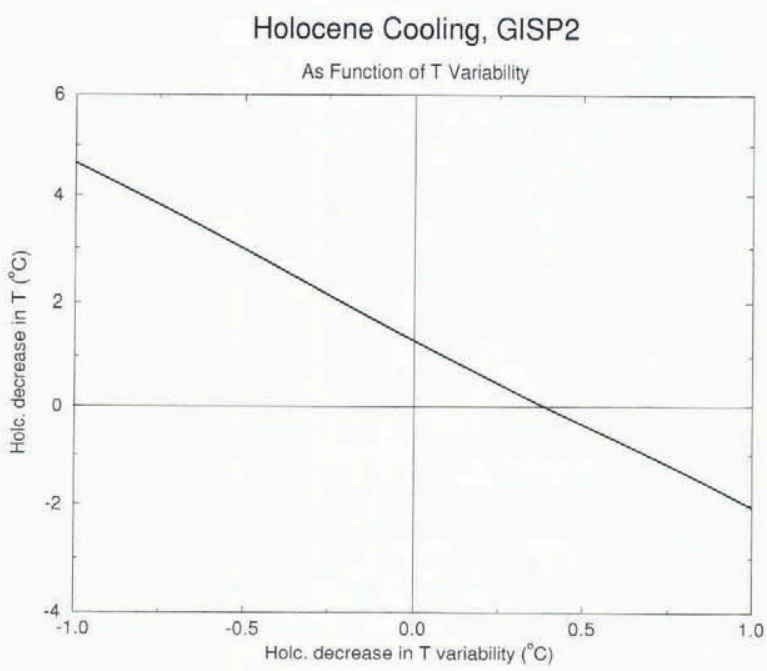

\begin{abstract}
Fig. 2. Combinations of cooling of mean summertime temperature over the most recent $7 \mathrm{ka}, \Delta T\left({ }^{\circ} \mathrm{C}\right)$ and decrease in variability of summertime daily mean temperatures over this period, $\Delta \sigma\left({ }^{\circ} \mathrm{C}\right)$, that are consistent with the observed change in melt frequency and the assumption that summertime daily mean temperatures have been normally distributed throughout this time with a recent standard deviation of $3.5^{\circ} \mathrm{C}$. We prefer the interpretation with $\Delta \sigma=0$.
\end{abstract}

\section{DISCUSSION}

We lack any objective way of separating change in midsummer temperature from change in mid-summer temperature variability, to choose a unique history from Figure 2. One might suppose that warming would decrease the variability, at least as regards occurrence of anomalously high temperatures. Air masses reaching GISP2 near the summit of the ice sheet must travel hundreds of kilometers over ice-covered terrain which cannot have a surface temperature above $0^{\circ} \mathrm{C}$. Thus, warmer air masses experience steeper temperature gradients to the surface and faster heat loss, making it difficult to advect especially warm air masses to GISP2. However, our experience at GISP2 during the summers of 1989 - 93 which did not include formation of any melt features) shows that many warm days are associated with high pressure and sinking air that may have traveled to the site aloft and had minimal interaction with the icesheet surface; if so, then warming need not be accompanied by a reduction in temperature variability toward warm days. We thus believe that much or all of the signal in the melt features is related to change in summertime temperatures.

Our calculations clearly involve many assumptions. However, the calculations are not especially sensitive to most of them. Almost any interpretation of the change in GISP2 melt frequency as a change in temperature, together with the comparison between site $\mathrm{A}$ and GISP2, will yield a GISP2 cooling over the most recent
$7 \mathrm{ka}$ within a few tenths of a degree of our estimate of $1.3^{\circ} \mathrm{C}$. We do not claim accuracy higher than a few tenths of a degree.

Temperature change may represent climatic change or change in altitude of the ice-sheet surface above sea level through the vertical lapse rate. Recent model results (Letréguilly and others, 1991; Anandakrishnan and others, 1994; Bolzan and others, 1995) indicate that the ice-divide thickness in central Greenland has changed only tens of meters since the Last Glacial Maximum, and probably less over the most recent $7 \mathrm{ka}$. After allowing for isostatic compensation and an adiabatic lapse rate of about $1^{\circ} \mathrm{C}$ per $100 \mathrm{~m}$ or slightly less, this is equivalent to less than a few tenths of a degree Celsius change over the most recent $7 \mathrm{ka}$. Some models suggest somewhat larger thickness changes on the glacial-interglacial time-scale (Reeh, 1984; Cutler and others, 1995), although the change over the most recent few thousand years is still likely to have been small. We believe that the melt signal at GISP2 is primarily climatic rather than an elevation effect.

\section{INTERCOMPARISONS}

Because melt is a summer-season thermometer only, it can be combined with other data on mean annual temperature to gain information about non-summertime temperature changes. Three thermometers are commonly used on ice sheets: stable-isotopic composition of the ice, borehole temperature, and occurrence of melt. Stableisotopic composition records the temperature at times when precipitation occurs; in central Greenland, precipitation and accumulation probably occur year-round, but with slightly more in late summer to fall and slightly less in winter (Bromwich and others, 1993; paper in preparation by C.A. Shuman). Borehole temperature probably comes closest to recording mean annual temperature in the dry-firn zone.

Analyses and calibration of oxygen-isotopic ratios (Grootes and others, 1993), joint oxygen/deuterium ratios (Barlow and others, 1993) and borehole temperature profiles (paper in preparation by G. Clow and E. Waddington) for the GISP2 core are ongoing, and strong conclusions are not yet possible. Some results for the nearby GRIP hole are given by Johnsen and others (1992), Dahl-Jensen and others (1993) and Gundestrup and others (1993). The data from Johnsen and others (1992) are shown in Figure 3, after smoothing with a 1000 a running average. The GISP2 data Grootes and others, 1993) are similar. The isotopic ratios have been converted to temperatures using the calibration of Cuffey and others $(1992,1994)$ with no corrections for change in isotopic composition of source waters. Following the end of the last ice age, the isotopic composition of the oceans became progressively lighter owing to ice-sheet melting, but variation in the rate of input vs mixing of meltwaters in the North Atlantic could have caused local trends to differ from global ones. Corrections in the neighborhood of $1^{\circ} \mathrm{C}$ are possible (e.g. Fisher, 1992). However, the cooling toward the present in the latter part of the Holocene shown in both the melt record and the isotopic record from central Greenland is more recent than most of the meltwater input to the ocean. The indications from 


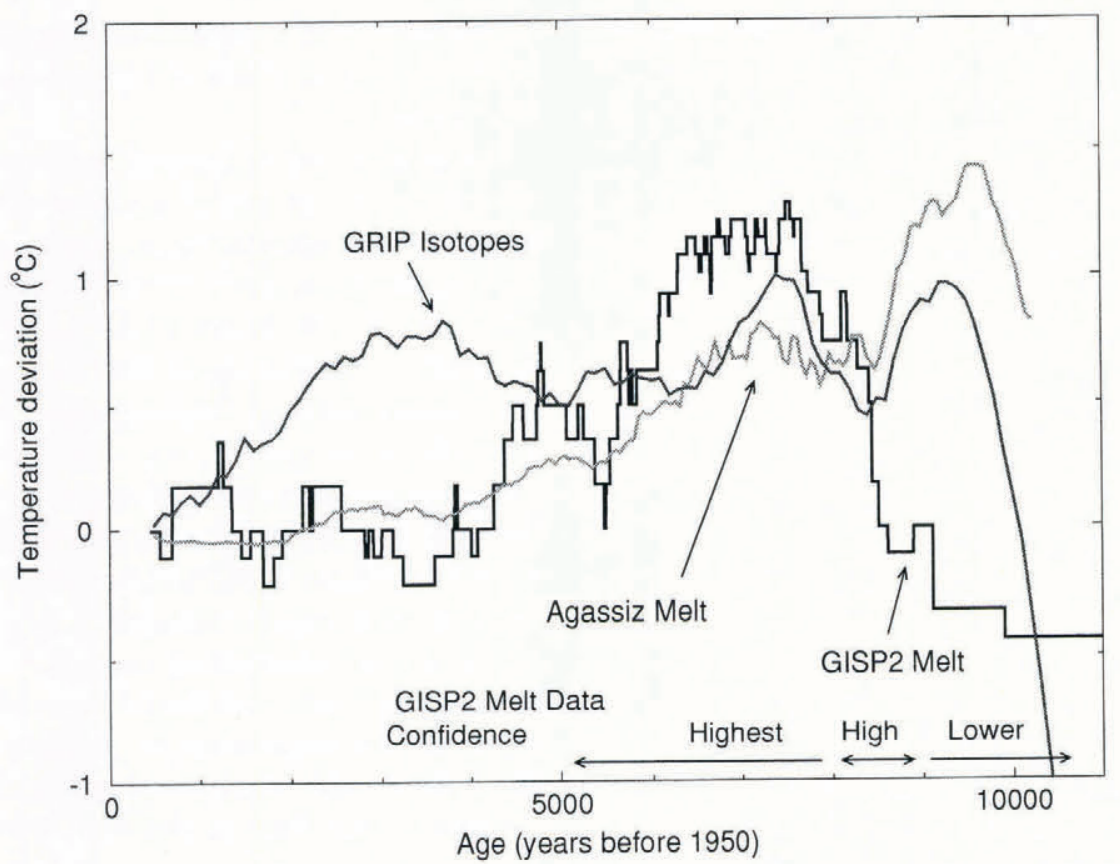

Fig. 3. Comparison of 1000 a running means of temperature deviations estimated from our calibration of the GISP2 melt record, from the oxygen-isotopic record of the GRIP core (Johnsen and others, 1992) calibrated following Cuffey and others (1992, 1994), and from the melt record of the Agassiz Ice Cap (Koerner and Fisher, 1990); see text for details of calculations.

GISP2 and GRIP then are that mean annual and accumulation temperatures have cooled by about $1^{\circ} \mathrm{C}$ over the most recent few thousand years, similar to the summertime cooling indicated by melt. If so, then nonsummer temperatures have cooled over the same interval.

In Figure 3, we also show estimated temperature changes over the last $11 \mathrm{ka}$ from melt in the Agassiz Ice Cap (Koerner and Fisher, 1990). Koerner and Fisher suggested that the signal in their time series was in the range of $2^{\circ} \mathrm{C}$, so we converted their record to temperature change using this. For both the GISP2 and Agassiz melt records, we used a normal distribution with the same standard deviation to convert melt occurrence to temperature, with a linear extrapolation from modern conditions to zero melt. We note that the simpler model in which melt varies linearly with temperature produces curves that can be distinguished from those in Figure 3 only by careful examination.

The curves in Figure 3 have been smoothed with a 1000 a running mean (Koerner and Fisher reported average melt in 50 a intervals, so we used a 20 interval running mean). The time-scale for the Agassiz record assumed that the abrupt increase in oxygen-isotopic ratio at the start of the Holocene corresponded to the termination of the Younger Dryas event in Greenland ice cores, and adopted the age of $10750 \mathrm{BP}$ for that termination. That termination has been re-dated to about $11600 \mathrm{BP}$ (e.g. Johnsen and others, 1992; Alley and others, 1993), so we have applied a linear transformation to the Agassiz age scale so that the warming at the end of the Younger Dryas has the same age as that adopted for GISP2. A linear transformation is not strictly correct (the recent parts of the Agassiz core were dated accurately), but at the $1000 \mathrm{a}$ averaging length this difference is insignificant.
The curves show certain consistent features: a warming following the end of the Younger Dryas, a cold event about $8000-8500 \mathrm{BP}$, a second warm period centered on $7500 \mathrm{BP}$, and a cooling toward the present. The $8500 \mathrm{BP}$ cold event is certainly most prominent in the isotopic record (see also Dansgaard and others, 1993; Grootes and others, 1993) but is suggested in the other two records. The 9000-10000 BP period appears much warmer in the isotopes and the Agassiz melt than in the GISP2 melt; however, we cannot guarantee that we have observed all melt features at that time, owing to questions about bubble enclathratization. Koerner and Fisher (1990) also note that some fraction of the Agassiz signal may represent isostatic rebound causing cooling, which would have been most pronounced in the earlier parts of the record, and the isotopic record could reflect changes in source-water composition. We plan to re-examine the GISP2 core following further relaxation in hope of learning whether the low melt frequency of the early Holocene at GISP2 is an interesting climatic feature or an artifact of physical processes in the ice.

It would be easy to over-interpret these curves, and we urge the reader to avoid doing so. The melt (and isotopic) calibrations are somewhat uncertain, the melt signal can saturate (it cannot show cooling below the level of zero melt in a window of some length), and so on. For example, the differences in rate of cooling in the isotopic and melt records from central Greenland over the most recent $7 \mathrm{ka}$ are interesting but are not highly statistically significant owing to the uncertainties associated with the sparseness of the melt features. Also, we note that we cannot use melt features at GISP2 to assess any global warming or post-Little Ice Age warming, because the melt features are too sparse to allow accurate statistical analyses over such short periods. 
Orbital calculations (Berger, 1978, 1979) show that summertime insolation at high northern latitudes has been decreasing over the last $9 \mathrm{ka}$ (Fig. 1), whereas wintertime insolation has been increasing over this time. The general-circulation-model simulations of Kutzbach and Guetter (1986) estimate that the decrease in summer insolation (when coupled with changes in other boundary conditions) would have caused summer cooling of around $2{ }^{\circ} \mathrm{C}$ in central Greenland, similar to our results. Those model calculations yield little winter temperature change over Greenland, with the sign dependent on location on the continent. This result should be testable once borehole and isotopic-temperature analyses are completed for the GISP2 and GRIP sites; preliminary indications are that both non-summer and summer in central Greenland have cooled over the most recent few thousand years, and that summertime cooling extended to Arctic Canada.

\section{CONCLUSIONS}

The frequency of melting at the GISP2 site in central Greenland has decreased significantly from a maximum about 7000-7500 BP. This could have been caused by a change in summer temperature variability over time, but probably represents a cooling of summer temperatures. Calibration of this signal suggests that the cooling has been within a few tenths of a degree of $1.3^{\circ} \mathrm{C}$. We interpret available ice-flow-modeling results as indicating little change in ice-surface elevation through the atmospheric lapse rate over this time, so the signal is probably climatic rather than glaciological.

Preliminary results from stable-isotopic and boreholetemperature thermometry suggest similar change in accumulation-weighted and mean annual temperatures to that seen in summertime temperatures, suggesting a year-round cooling. Comparison to the melt record from the Agassiz Ice Cap, Arctic Canada (Koerner and Fisher, 1990), suggests some regional coherence. Early Holocene warmth centered on roughly $9500 \mathrm{BP}$ was followed by a cold event centered about $8000-8500 \mathrm{BP}$, a warm period centered about 7000-7500 BP, and a cooling to the present, with an amplitude for this most recent cooling of roughly $1{ }^{\circ} \mathrm{C}$. The $9500 \mathrm{BP}$ warmth appears minimal in the GISP2 melt record but strong in the Agassiz melt and GRIP and GISP2 isotopic records, but we cannot tell to what extent this is an artifact of bubble-enclathratization processes in the GISP2 core or of source-water changes in the isotopic records and isostatic rebound in the Agassiz melt record.

\section{ACKNOWLEDGEMENTS}

We thank the GISP2 Science Management Office, the Polar Ice Coring Office and the New York 109th Air National Guard for logistical support, and G. Clow, D. Fisher, P. Grootes, A. Gow, S. Johnsen, R. Koerner, D. Meese, C. Shuman, C. Stearns, M. Stuiver, E. Waddington and two anonymous reviewers for helpful suggestions or access to unpublished data. This research was supported in part by the U.S. National Science Foundation (grants OPP-8822027 and its continua- tion), and by the D. and L. Packard Foundation and NASA/EOS.

\section{REFERENCES}

Alley, R. B. and B. R. Koci. 1988. Ice-core analysis at site A, Greenland: preliminary results. Ann. Glaciol., 10, $1-4$.

Alley, R. B. and 10 others. 1993. Abrupt increase in snow accumulation at the end of the Younger Dryas event. Nature, 362 6420), 527-529.

Anandakrishnan, S., R. B. Alley and E. D. Waddington. 1994. Sensitivity of the ice-divide position in Greenland to climate change. Geophys. Res. Lett., $21(6), 441-444$.

Barlow, L. K., J. W. C. White, R. G. Barry, J. C. Rogers and P. Grootes. 1993. The North Atlantic oscillation signature in deuterium and deuterium excess signals in the Greenland Ice Sheet Project 2 ice core, 1840-1970. Geophys. Res. Lelt., 20 24), 2901-2904.

Benson, C.S. 1962. Stratigraphic studies in the snow and firn of the Greenland ice sheet. SIPRE Res. Rep. 70.

Berger, A. L. 1978. Long-term variations of caloric insolation resulting from the Earth's orbital elements. Quat. Res., 9 2), 139-167.

Berger, A. 1979. Insolation signatures of Quaternary climatic changes. Nuovo Cimento, 2C, 63-87.

Bolzan, J.F. and others. 1995. Constraints on Holocene ice-thickness changes in central Greenland from the GISP2 ice-core data. Ann. Glaciol., 21 (see paper in this volume).

Bromwich, D. H., F. M. Robasky, R. A. Keen and J. F. Bolzan. 1993. Modeled variations of precipitation over the Greenland ice sheet. J. Climate, 6 7), 1253-1268.

Cuffey, K. M., R. B. Alley, P. M. Grootes and S. Anandakrishnan. 1992. Toward using borehole temperatures to calibrate an isotopic paleothermometer in central Greenland. Global and Planetary Change, 98 (2-4), 265-268.

Cuffey, K. M., R.B. Alley, P.M. Grootes, J. M. Bolzan and S. Anandakrishnan. 1994. Calibration of the $\delta^{18} 0$ isotopic paleothermometer for central Greenland, using borehole temperatures. 7 . Glaciol., 40 135), 341-349.

Cutler, N. N. and others. 1995. The effect of ice-sheet thickness change on the accumulation history inferred from the GISP2 layer thicknesses. Ann. Glaciol., 21 (see paper in this volume).

Dahl-Jensen, D., S.J. Johnsen and N.S. Gundestrup. 1993. GRIP temperature profile from the summit of the Greenland ice sheet. [Abstract.] 74 (43 Supplement), 90.

Dansgaard, W. and 10 others. 1993. Evidence for general instability of past climate from a 250-kyr ice-core record. Nature, 364 6434), 218 220.

Fisher, D. A. 1992. Possible ice-core evidence for a fresh melt water cap over the Atlantic Ocean in the Early Holocene. In Bard, E. and W. S. Broecker, eds. The last deglaciation: absolute and radiocarbon chronologies. Berlin, Springer-Verlag, 267-293.

Fujii, Y. and K. Kusunoki. 1982. The role of sublimation and condensation in the formation of ice sheet surface at Mizuho Station, Antarctica. 7. Geophys. Res., 87 C6), 4293-4300.

Gow, A.J. 1968. Deep core studies of the accumulation and densification of snow at Byrd Station and Little America V. Antarctica. CRREL Res. Rep. 197.

Gow, A. J. and T. Williamson. 1971. Volcanic ash in the Antarctic ice sheet and its possible climatic implication. Earth Planet Sci. Lell., $13(17), 210-218$.

Gow, A.J., D. A. Meese and R. B. Alley. 1993. Discontinuities including possible distortion of the environmental record in cores of deep basal ice from central Greenland. [Abstract.] EOS, 74 (43 Supplement), 84

Grootes, P. M., M. Stuiver, J. W. C. White, S. Johnsen and J. Jouzel. 1993. Comparison of oxygen isotope records from the GISP2 and GRIP Greenland ice cores. Nature, 366 6455), 552-554.

Gundestrup, N.S., D. Dahl-Jensen, S.J. Johnsen and A. Rossi. 1993. Bore-hole survey at dome GRIP 1991. Cold Reg. Sci. Technol., 21(4), 399- 402 ,

Herron, M. M., S. L. Herron and C. C. Langway, Jr. 1981. Climatic signal of ice melt features in southern Greenland. Nature, 293 (5831), 389-391.

Johnsen, S.J. and 9 others, 1992. Irregular glacial inter-stadials recorded in a new Greenland ice core. Nature, 359 6393), 311-313.

Kameda, T., H. Narita, H. Shoji, F. Nishio, Y. Fujii and O. Watanabe 1995. Melt features in ice cores from Site J, southern Greenland: some implications for summer climate since AD 1550. Ann. Glaciol., 21 (see paper in this volume).

Koerner, R. M. 1977. Devon Island ice cap: core stratigraphy and climate. Science, $196(4285), 15-18$. 
Koerner, R. M. and D. A. Fisher. 1990. A record of Holocene summer climate from a Canadian high-Arctic ice core. Nature, 343 (6259), $630-631$.

Kutzbach, J. E. and P.J. Guetter. 1986. The influence of changing orbital parameters and surface boundary conditions on climate simulations for the past 18,000 years. J. Atmos. Sci., 43(16), 1726-1759.

Langway, C. C., Jr. 1967. Stratigraphic analysis of a deep ice core from Greenland. CRREL Res. Rep. 77.

Letréguilly, A., N. Reeh and P. Huybrechts. 1991. The Greenland ice sheet through the last glacial-interglacial cycle. Palaeogeogr., Palaeoclimatol., Palaeoecol., 90(4), 385-394.
Peel, D. A., R. Mulvaney and B. M. Davison. 1988. Stable-isotope/airtemperature relationships in ice cores from Dolleman Island and the Palmer Land Plateau, Antarctic Peninsula. Ann. Glaciol., 10, 130-136.

Reeh, N. 1984. Reconstruction of the glacial ice covers of Greenland and the Canadian Arctic islands by three-dimensional, perfectly plastic ice-sheet modelling. Ann. Glaciol., 5, 115-121.

Schott, C., E. D. Waddington and C.F. Raymond. 1992. Predicted time-scales for GISP2 and GRIP boreholes at Summit, Greenland. $f$. Glaciol., 38 (128), 162-168.

Taylor, K. and 6 others. 1992. Ice-core dating and chemistry by directcurrent electrical conductivity. J. Glaciol., 38(130), 325-332. 